\title{
Acta Oecologica
}

\section{Changes in spatial point patterns of pioneer woody plants across a large tropical landslide}

\author{
Eduardo Velázquez , Marcelino De la Cruz , Antonio Gómez-Sal
}

\begin{abstract}
A B S T R A C T
We assessed whether the relative importance of positive and negative interactions in early successional communities varied across a large landslide on Casita Volcano (Nicaragua). We tested several hypotheses concerning the signatures of these processes in the spatial patterns of woody pioneer plants, as well as those of mortality and recruitment events, in several zones of the landslide differing in substrate stability and fertility, over a period of two years (2001 and 2002). We identified all woody individuals with a diameter $>1 \mathrm{~cm}$ and mapped them in 28 plots measuring $10 \times 10-\mathrm{m}$. On these maps, we performed a spatial point pattern analysis using univariate and bivariate pair-correlation functions; $\mathrm{g}(r)$ and $g_{12}(r)$, and pairwise differences of univariate and bivariate functions. Spatial signatures of positive and negative interactions among woody plants were more prevalent in the most and least stressful zones of the landslide, respectively. Natural and human-induced disturbances such as the occurrence of fire, removal of newly colonizing plants through erosion and clearcutting of pioneer trees were also identified as potentially important pattern-creating processes. These results are in agreement with the stress-gradient hypothesis, which states that the relative importance of facilitation and competition varies inversely across gradients of abiotic stress. Our findings also indicate that the assembly of early successional plant communities in large heterogeneous landslides might be driven by a much larger array of processes than previously thought.
\end{abstract}

\section{Introduction}

The stress-gradient hypothesis predicts that the relative importance of positive and negative interactions in plant communities varies inversely across gradients of abiotic stress (Bertness and Callaway, 1994). These two types of processes also have a marked effect upon the spatial patterns of surviving, dead and recruited plant individuals (Schenk et al., 2003; Malkison and Kadmon, 2007).

In highly stressful environments such as semi-arid shrublands or savannas (Callaway et al., 2002), and high-mountain plant communities (Fajardo et al., 2008), the presence of neighbours around focal plants usually ameliorates environmental conditions.
These positive interactions lead to aggregated distributions of individuals (Schleicher et al., 2011). In sites subjected to vegetation recovery, aggregated patterns become more evident as a consequence of the greater significance of positive interactions over the first few years of succession (Felinks and Wiegand, 2008). Moreover, facilitation usually generates spatial patterns characterised by a high degree of aggregation, on one hand, among dead individuals and on the other hand, among surviving ones (Malkison and Kadmon, 2007). Facilitation also generates higher pre-mortality densities around surviving individuals than around dead ones (i.e. density-dependent survival; Raventós et al., 2010). The first colonizers may also facilitate the establishment of individuals arriving subsequently by increasing substrate stability, capturing plant propagules and creating fertility islands with higher water and nutrient contents (Walker and del Moral, 2003). All these processes create positive spatial associations (i.e. attraction) between established and newly recruited individuals (Felinks and Wiegand, 2008). 

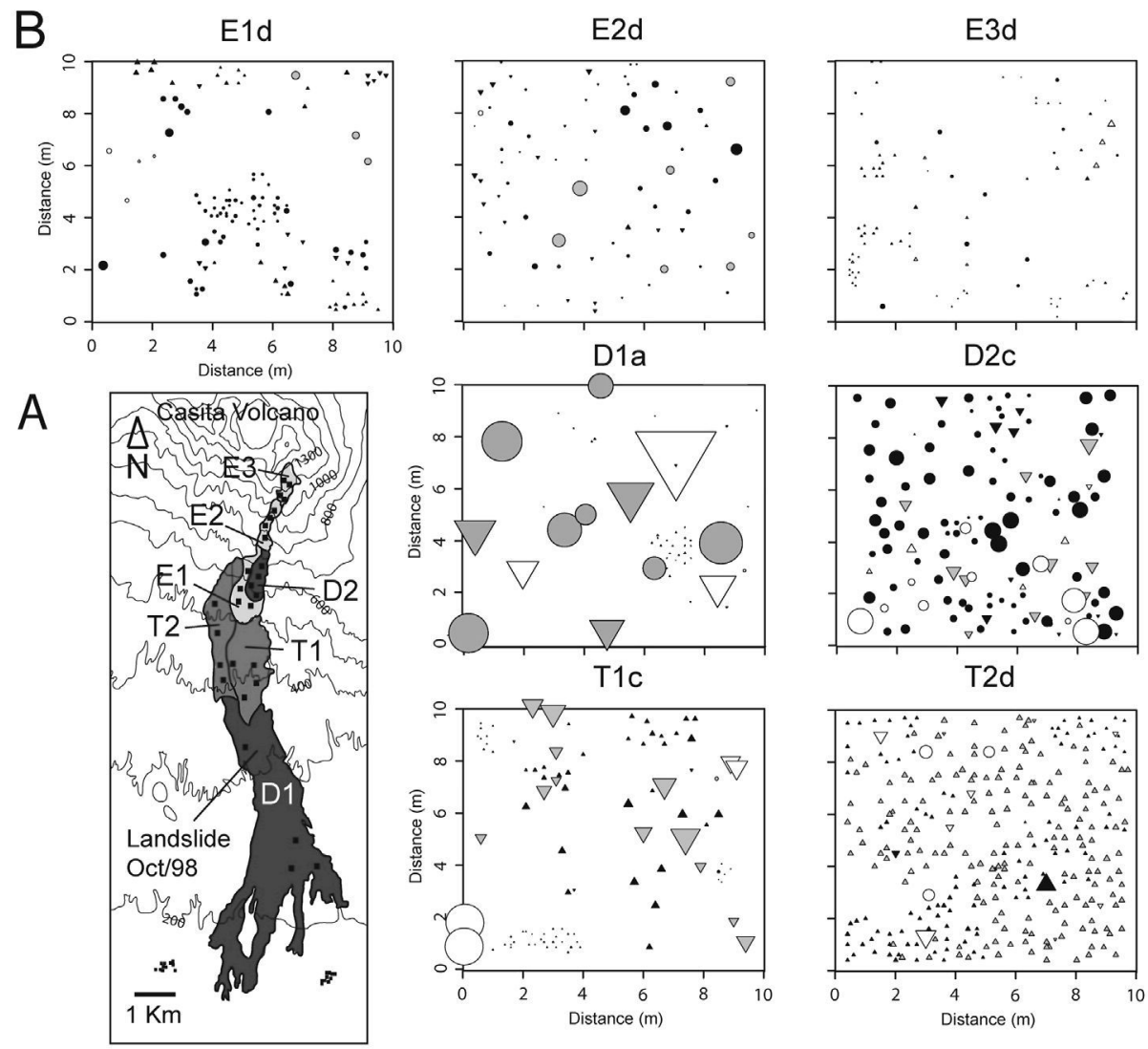

$\mathrm{T} 2 \mathrm{~d}$
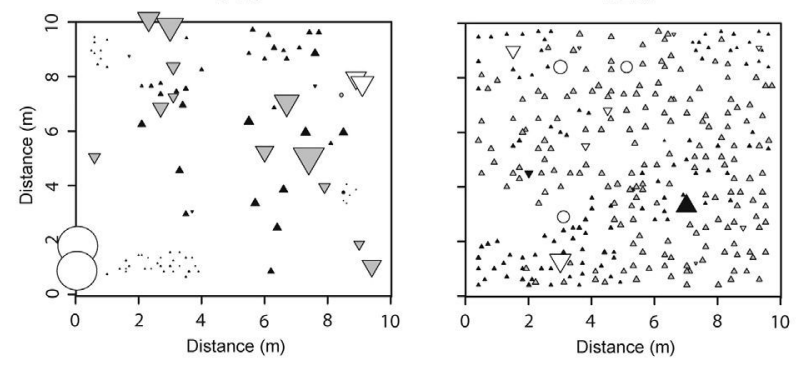

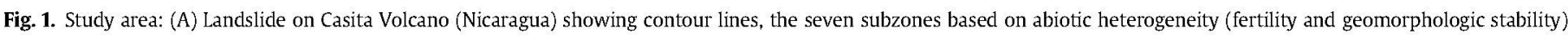

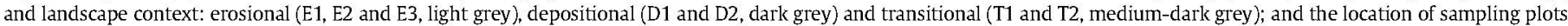

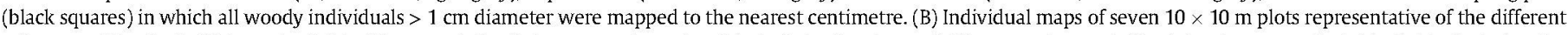

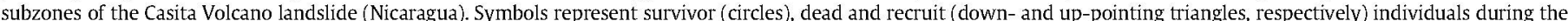

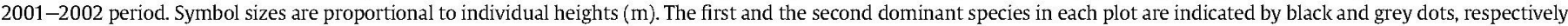

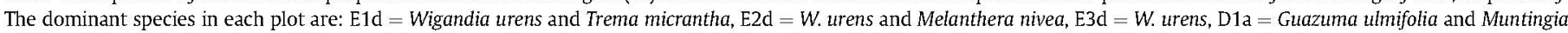
calabura, $\mathrm{D} 2 \mathrm{c}=T$. micrantha and $W$. urens, T1c $=$ Desmodium nicaraguense and $T$. micrantha, and $\mathrm{T} 2 \mathrm{~d}=D$. nicaraguense and Indigofera guatimalensis.

Conversely, in less stressful environments, where competition usually prevails, plant individuals are regularly spaced (Schenk et al., 2003; Moustakas et al., 2008), and these regular patterns become more evident over time (Stoll and Bergius, 2005). Negative interactions also cause aggregated patterns of dead individuals (Jacquemyn et al., 2010), and repulsion or segregation between these and surviving individuals (Raventós et al., 2010, 2012). Moreover, in tree stands located on fertile sites, resource acquisition is rapid and mortality of individuals increases in the proximity of neighbours, which create non-random patterns of densitydependent mortality (Yu et al., 2009; Raventós et al., 2010).

The stress-gradient hypothesis, however, does not always apply (Callaway and Pugnaire, 2008). In stressful environments, patchy distribution of soil resources may lead to aggregated spatial patterns without necessarily involving positive interactions among plants (Barot and Gignoux, 2003). In this case, the spatial signature of mortality will not be affected by proximity of surviving individuals, but rather by additional processes (Getzin et al., 2006). Moreover, when resources are heterogeneously distributed in space, survival of individuals with better access to them will be disproportionately favoured in relation to the neighbouring plants (i.e. asymmetric contest competition; Colasanti and Hunt, 1997). This process will generate spatial patterns of attraction between dead and surviving individuals (Jacquemyn et al., 2010; Raventós et al., 2010).
Changes in the spatial patterns resulting from the relative importance of positive and negative interactions in plant communities have mostly been analyzed across gradients of abiotic stress in semi-arid (e.g. Malkison and Kadmon, 2007) and high-mountain (e.g. Fajardo et al., 2008) ecosystems of temperate latitudes, but to our knowledge, not in landslides. However, landslides appear to constitute highly adequate sites for testing predictions of the stress gradient hypothesis. Landslides are heterogeneous disturbances that comprise zones differing significantly in fertility and geomorphologic stability (Restrepo et al., 2009). Pathways of ecological succession differed greatly among these zones (Walker et al., 1996). In the upper or erosional zones, where original soil and vegetation are entirely removed, germination, establishment and survival of woody pioneers are severely limited by patchy distributions of soil resources (Fetcher et al., 1996). Once established, however, early successional woody plants can facilitate the establishment of late successional ones by increasing soil nutrient and organic matter contents (Shiels et al,, 2006; Walker et al., 2013), and decreasing the cover of forbs (Walker et al., 2010b). In the lower or depositional zones, which have a rich biological legacy consisting of the original soils and heterogeneous mixtures of broken plant parts, seeds, and rock fragments from the upper zones, there is often competition for light among pioneer trees and shrubs during early succession (Velázquez et al., 2009b). On large landslides it is also possible to distinguish marked transitional zones through which the landslide 
mass flowed and in which successional trajectories are highly unpredictable (e.g. Francescato et al., 2001).

In the present paper, we assess whether spatial point patterns of pioneer woody plants vary between the different zones of a large landslide on Casita Volcano (Nicaragua), reflecting the occurrence of positive and negative interactions in the most and least stressful sites, respectively. On this landslide, during the first four years following disturbance (1999-2002), successional changes differed greatly among erosional, depositional and transitional zones (Velazquez and Gómez-Sal, 2008, 2009a). In the erosional zone, plant communities were dominated by small shrubs and tree saplings, and soil nutrient content was identified as the main driver of change in species richness and composition. In contrast, the depositional zone was rapidly colonized by pioneer trees, which attained a relatively large size. In the transitional zone, early successional communities experienced a noteworthy change in species composition as a result of fires started by peasants from the nearby zones, which spread into the area affected by the landslide. Postfire colonization of new opportunistic species usually causes dramatic changes in the spatial patterns of plant communities, increasing either aggregation or regularity (Rebertus et al., 1989). Repulsion between the spatial patterns of these species may also arise as a consequence of negative interactions among them (De Luis et al., 2008).

In particular, we tested four ecologically informed, a-priori hypotheses; (1) In the erosional zones, positive interactions will prevail, causing several spatial signatures; aggregated patterns of woody plants, an increase in their spatial aggregation over time, aggregation within surviving individuals, spatial segregation among dead and surviving individuals, and a larger number of total neighbours around surviving individuals than around dead ones; i.e. density-dependent survival. We also expect new recruits to be spatially attracted to surviving individuals. Alternatively, in the erosional zones (2), spatial patterns of mortality of pioneer woody plants may be determined by a patchy distribution of soil resources. In this case, mortality will be higher where resources are less available, and the spatial patterns of dead individuals will not be affected by those of surviving ones, but rather by other, additional patterns. Moreover, in the erosional zones, (3) asymmetric contest competition may lead to spatial patterns of attraction between surviving and dead individuals. In the depositional zones, where availability of soil resources is higher and these are more homogeneously distributed than in the erosional zones, (4) prevalence of competition will cause regular patterns among colonizing plants, an increase in this regularity over time, and a larger number of total neighbours around dead individuals than around surviving ones; i.e. density-dependent mortality. In the transitional zones, (5) there will be big changes in the spatial patterns of plant communities and repulsion between those of the dominant colonizing species may also arise.

\section{Materials and methods}

\subsection{Study site}

The present study was conducted on a landslide situated on the Casita Volcano $\left(12^{\circ} 41^{\prime} \mathrm{N} ; 85^{\circ} 57^{\prime} \mathrm{W}\right)$. This landslide was triggered by an exceptional rainfall event ( $500 \mathrm{~mm}$ in $24 \mathrm{~h}$ ) on 30 October 1998, during Hurricane Mitch, and exhibits an altitude range of 150-1350 $\mathrm{m}$ a.s.l., an area of $11.21 \mathrm{~km}^{2}$, and a complex geomorphology (Kerle et al., 2003). The landslide is surrounded by a highly heterogeneous landscape dominated by remnants of tropical dry forests within an agricultural matrix. The area is densely populated (172 habs. $/ \mathrm{km}^{2}$ ) and human activities such as hunting, and burning and clearing of vegetation are common (Velázquez and Gómez-Sal, 2007).

During a pilot study in September 1999, we identified the three major zones in the landslide; erosional (E), depositional (D) and transitional $(\mathrm{T})$. These zones reflected the uppermost and steepest area where the landslide began, the lowermost and flattest area where the landslide mass settled, and the moderately steep area through which the landslide mass flowed, respectively (Martin et al., 2002). Based upon the adjacent vegetation in each zone, we also identified three subzones within the erosional zone (E1, E2 and E3) and two within both the depositional (D1 and D2) and transitional (T1 and T2) zones (Fig. 1). These subzones varied greatly with regard to slope, soil texture, nutrient contents, and species composition and diversity of woody pioneer communities (Velázquez and Gómez-Sal, 2008). The erosional zone was dominated by shrubs such as Wigandia urens and Melanthera nivea, and saplings of the pioneer tree Trema micrantha. The depositional zone was dominated by stands of juvenile individuals of the latter species, as well as Muntingia calabura, reaching up to $2-5 \mathrm{~m}$ height and with a crown diameter of $0.5-1 \mathrm{~m}$. These stands were particularly

\section{Table 1}

Total numbers of woody plant individuals, rates of survivorship, mortality and recruitment, and dominant species in the erosional (E1, E2 and E3), depositional (D1 and $\mathrm{D} 2$ ) and transitional (T1 and T2) subzones of the landslide on Casita Volcano (Nicaragua). Rates of survivorship, mortality and recruitment are calculated based on the total number of individuals per subzone. Proportions of the total number of surviving, dead and/or recruited individuals making up each dominant species are also indicated.

\begin{tabular}{|c|c|c|c|c|c|}
\hline Subzone & $\begin{array}{l}\text { Total number } \\
\text { of individuals }\end{array}$ & $\begin{array}{l}\text { Rate of } \\
\text { survivorship } \\
(\%)\end{array}$ & $\begin{array}{l}\text { Rate of } \\
\text { mortality } \\
(\%)\end{array}$ & $\begin{array}{l}\text { Rate of } \\
\text { recruitment } \\
(\%)\end{array}$ & $\begin{array}{l}\text { Dominant } \\
\operatorname{species}^{a}(\%)\end{array}$ \\
\hline E1 & 289 & 36.7 & 25.7 & 45 & $\begin{array}{l}\text { Wigandia urens } \\
(52.2,51.8, \\
20.1) \\
\text { Trema } \\
\text { micrantha }(25, \\
33.4)\end{array}$ \\
\hline E2 & 225 & 40.2 & 37.7 & 21.3 & $\begin{array}{l}\text { Wigandia urens } \\
(47.7,56.9) \\
\text { Melanthera } \\
\text { nivea }(20.5 \text {, } \\
12.5)\end{array}$ \\
\hline E3 & 63 & 15.8 & 28.1 & 56.1 & $\begin{array}{l}\text { Wigandia urens } \\
(69.7,19.2, \\
46.1) \\
\text { Verbesina } \\
\text { turbacensis ( } 6.9, \\
29.9)\end{array}$ \\
\hline D1 & 116 & 29.7 & 44.4 & 25.9 & - \\
\hline D2 & 275 & 54.8 & 32.5 & 53.7 & $\begin{array}{l}\text { Trema } \\
\text { micrantha (86.4, } \\
27.6)\end{array}$ \\
\hline T1 & 214 & 26.5 & 33.7 & 46.4 & $\begin{array}{l}\text { Desmodium } \\
\text { nicaraguense } \\
\text { (46.7) } \\
\text { Desmodium } \\
\text { incamum } \\
(39.51)\end{array}$ \\
\hline $\mathrm{T} 2$ & 534 & 14.7 & 12.4 & 72.9 & $\begin{array}{l}\text { Desmodium } \\
\text { nicaraguense } \\
(49.9) \\
\text { Indigofera } \\
\text { guatimalensis } \\
(47.7)\end{array}$ \\
\hline
\end{tabular}

a In the erosional subzones (E1, E2 and E3); proportions (\%) of surviving, dead and when present, recruited individuals with regard to total number of individuals. In the depositional subzone D2; proportions of surviving and dead individuals. In the transitional subzones (T1 and T2); proportions of recruited individuals. In depositional subzone D1 there were no species comprising both, surviving and dead individuals. 

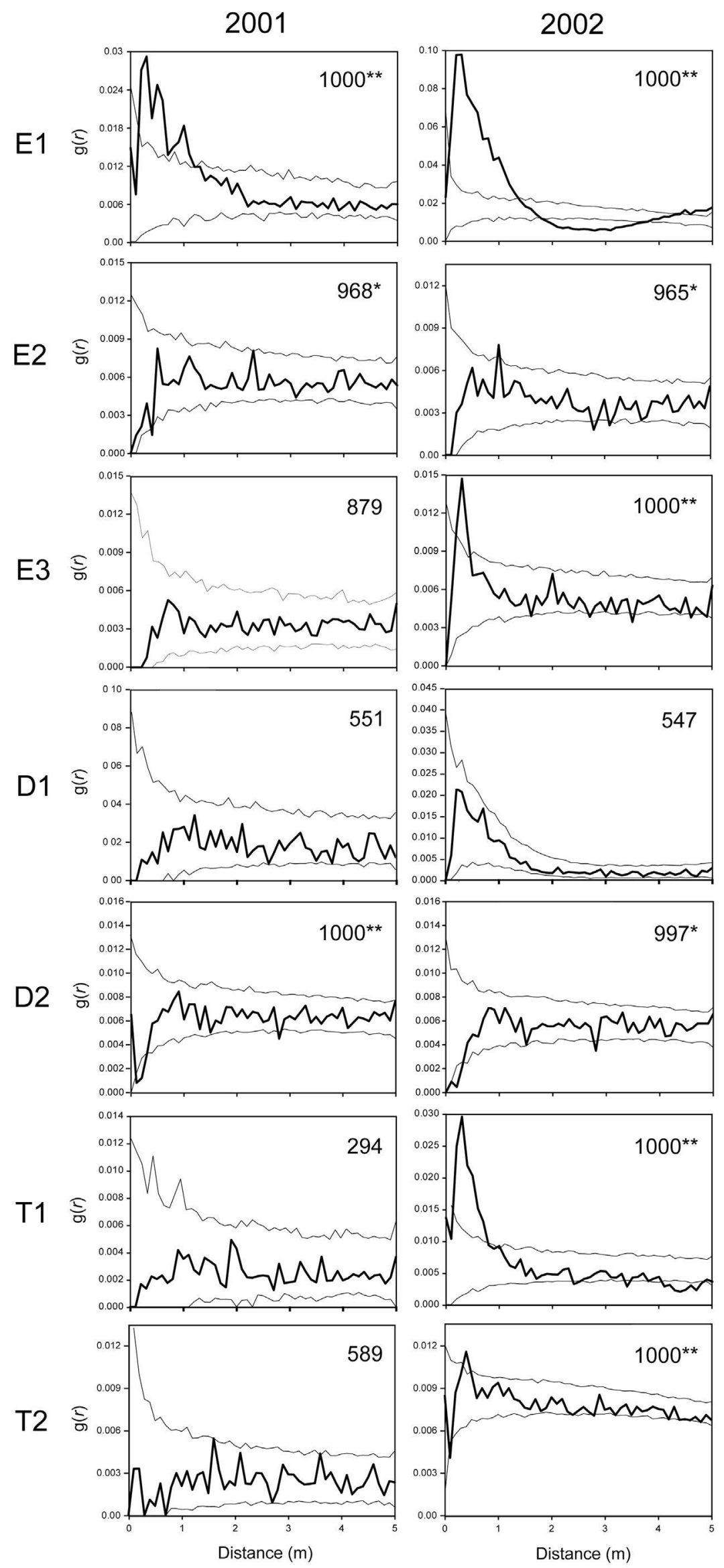
dense in subzone D2. In subzone D1, from 2001 to 2002, some individuals of T. micrantha were felled. During this period, fires started by local farmers spread into subzones T1 and T2, burning the existing vegetation, and enhancing the spread of the shrubs Desmodium nicaraguense and Indigofera guatimalensis.

\subsection{Sampling}

In the year 2000, in each of the seven subzones, we established a long-term permanent $10 \times 10 \mathrm{~m}$ plot and in 2001 we added three additional $10 \times 10 \mathrm{~m}$ plots (each assigned a letter, a through $\mathrm{d}$ ) to each subzone. This plot size is adequate for study of spatial patterns of regeneration (Fajardo and Alaback, 2005) and early succession (Rice et al., 2012) because, in the plant communities in which these two processes are ongoing, there is a large abundance of shrubs and tree saplings and plant-plant interactions occur mostly at small spatial scales. In 2001, 2002 the study included 28 total plots. In these two years, at the end of the rainy season (October to December), within each plot, we identified to the species level and mapped to the nearest centimetre all woody individuals $>1 \mathrm{~cm}$ diameter, with the use of a measuring tape. On the resulting point maps we considered as surviving, dead and recruited woody individuals, all those that survived, disappeared and appeared from one year to the next, respectively (Malkison and Kadmon, 2007). Species taxonomy and nomenclature follow Stevens et al. (2001).

\subsection{Spatial point pattern analysis}

To assess the spatial signature of the processes of interest in the subzones of the landslide on Casita Volcano between 2001 and 2002, we performed different spatial point pattern analyses on point maps obtained in each plot (Wiegand and Moloney, 2004). In particular, we used summary statistics based on univariate Ripley's $K(r)$ functions (Dixon, 2002), and univariate and bivariate paircorrelation functions, $g(r)$ and $g_{12}(r)$ (Stoyan and Stoyan, 1994). The univariate pair-correlation function $\mathrm{g}(r)$ can be defined as the expected density of points in a ring whose radius is $r$ and whose width is $d w$, centred on an arbitrary point, divided by the intensity $\lambda$ of the point pattern (i.e. number of points per unit area). The bivariate pair-correlation function $g_{12}(r)$ describes the spatial relationships between two patterns (represented by subscripts 1 and 2) and can be defined as the expected density of pattern 2 points in a ring whose radius is $r$ and whose width is $d w$ centred on an arbitrary pattern 1 point, divided by the intensity $\lambda_{2}$ of pattern 2 .

Before studying changes in spatial point patterns of woody plant individuals, we first assessed (and where necessary, corrected for) the occurrence of heterogeneity in the point patterns. Occurrence of heterogeneity may confound the spatial signatures and conditions the choice of an appropriate null model for analysing the processes of interest (Wiegand and Moloney, 2004). To this end, we computed univariate $K$-functions for each plot and compared them with the expectations of a null model of Complete Spatial Randomness (hereafter; CSR). Heterogeneity was identified by the presence of virtual aggregation, which is defined by significant and continuous positive deviations of CSR in a wide range of spatial neighbourhoods (Wiegand et al., 2007). We detected virtual aggregation in an appreciable number of plots (Table S1); consequently, in all of them, we tested the empirical $g$-function against a heterogeneous Poisson process (hereafter; HPP) (Getzin et al., 2006). According to this null model, the intensity $\lambda$ of the point pattern is not constant, but rather varies with location $(x, y)$ throughout the plot. The HPP is implemented by means of a circular moving window estimate $\left(\lambda^{R}\right)$ of the intensity function. According to this, a provisional point is placed in a random location within the study area, and this point is only retained with a probability given through $\lambda^{R}(x, y)$. The process is repeated until $n$ points are distributed (Wiegand and Moloney, 2004). This is basically a kernel estimate with a fixed bandwidth $R$ which represents the radius of the circular moving window (Bailey and Gatrell, 1995). In ecological terms, such fixed bandwidth represents the maximum distance at which second-order effects (i.e. resulting from plant-plant interactions) played a more significant role than that of first-order effects, caused by environmental heterogeneity, in determining the spatial point patterns of woody pioneer plants (Getzin et al., 2006). Plants usually interact with their neighbours up to a maximum distance of $2-2.5 \mathrm{~m}$, coinciding with their zones of resource depletion (Casper et al., 2003), but in some semi-arid shrubs these zones can extend well up to $5 \mathrm{~m}$ and beyond (Hartle et al., 2006). Moreover, in many plots of the Casita Volcano landslide, the influence of habitat preferences in the spatial patterns of woody pioneer plants might appear between 5 and $10 \mathrm{~m}$, due to their marked plot-scale abiotic heterogeneity (Velázquez, 2007; Velázquez and Gómez-Sal, 2008). Therefore, we finally considered a fixed bandwidth of $R=5 \mathrm{~m}$.

When testing against the HPP null model, values of $g(r)$ above the simulation envelopes indicate significant spatial aggregation at neighbourhoods of radius $r$. Conversely, values of $g(r)$ lower than the envelopes are indicative of significant regularity.

To test our predictions regarding the effects positive and negative interactions upon the spatial patterns of dead and surviving individuals (hereafter mortality analyses), we considered several summary statistics. To detect spatial aggregation in the pattern of both dead (subscript 1) and surviving (subscript 2) individuals (Hypothesis 1), we used summary statistics $g_{11}(r)$ and $g_{22}(r)$, respectively (Raventós et al., 2010, 2012). If any of these functions are above the simulation envelopes in neighbourhoods of radius $r$, either dead or surviving individuals will show significant aggregation. If values are below, dead or surviving individuals will show significant regularity. To detect attraction or segregation between dead and surviving individuals (Hypotheses 1-3), we used the summary statistic $g_{12}$ (r) (i.e. bivariate pair correlation function; Jacquemyn et al., 2010; Raventós et al., 2010). When the patterns of dead and surviving individuals show attraction or segregation at the spatial scale $r$, the values of $g_{12}(r)$ are above or below the simulation envelopes, respectively. To detect the occurrence of density-dependent survival or mortality (Hypotheses 1 and 4 , respectively), we used the test $g_{1,1+2}(r)-g_{2,1+2}(r)$ (Yu et al., 2009; Raventós et al., 2010). Values of this summary statistic below the simulation envelopes indicate that survivorship occurs preferentially in areas with high pre-mortality density at the spatial scale $r$ (i.e. density-dependent survival). Conversely, values of this function above the simulation envelopes will indicate the opposite pattern; density-dependent mortality. To evaluate whether mortality of individuals in the erosional zones is influenced by plot- 
scale abiotic heterogeneity (Hypothesis 2), we used the differences $g_{12}(r)-g_{11}(r)$ and $g_{21}(r)-g_{22}(r)$ as summary statistics (Getzin et al,, 2006). If patchy distribution of soil resources is influencing mortality of individuals, there will be an additional pattern within the dead individuals, independent from the pattern of surviving individuals. In this case, the number of dead individuals around surviving ones will be similar to the number of surviving individuals around other surviving ones; $g_{21}(r)-g_{22}(r)=0$. However, the number of dead individuals around other dead ones will be higher than the number of survivors around dead individuals; $g_{12}$ $(r)-g_{11}(r)<0$ (Getzin et al., 2006; Jacquemyn et al., 2010).

We tested all these summary statistics against a null model of random labelling (Goreaud and Pélissier, 2003). This null model considers a marked point pattern with two marks or labels (in this case, dead and surviving individuals), and its basic purpose involves establishing whether the process distributing the labels was random, and characterising potential departures from random labelling. A significant departure from the null model indicates non-random mortality, and use of the aforementioned summary statistics provides us with insights into the factors driving mortality.

To study the occurrence of facilitation processes between surviving and newly recruited individuals in the erosional zones (recruitment analyses, Hypothesis 1 ), we tested the $g_{12}(r)$ function against a null model of independence (Goreaud and Pélissier, 2003). This null model assumes that the two point patterns considered ( 1 and 2) are generated by independent processes; i.e. different colonization events for newly recruited (subscript 1 ) and surviving (subscript 2) individuals. Values of $g_{12}(r)$ above and below the simulation envelopes indicate, respectively, attraction and repulsion between these two patterns (He and Duncan, 2000).

In each plot, we tested our hypotheses 1 to 4 at community level (i.e. considering all woody plants regardless of their specific identity), but we also addressed them at population level (i.e. considering only individuals of the most abundant species in each subzone; Appendix B, Figs. S1 to S4). To determine the existence of negative interactions between the species that invaded transitional zones after fire, we first selected the two most dominant species (i.e. those with a higher proportion of recruited individuals with regard to the total) colonizing each transitional subzone in 2002. Thus, we focused on the interactions between Desmodium incanum and $D$. nicaraguense, and between $D$. nicaraguense and I. guatimalensis, because they comprised the largest number of recruited individuals (Table 1 ). We restricted the analyses of these two pairs of species to plots T1c and T2d, respectively, because they were the plots in which each one of these pairs of species was present.

As the number of woody plants was very low in many plots, to increase the statistical power of our spatial analyses, we combined results from all four plots in a master pair correlation function per subzone by means of the aggregation method proposed by Illian et al. (2008) (Appendix A). According to this method, we assumed that the patterns in each of the four plots were independent samples or "replicates" from a larger pattern per subzone (Law et al., 2009). Additionally, this approach enabled us to make inferences in relation to whole subzones rather than merely describing the spatial patterns of individual plots (Schenk et al,, 2003; De Luis et al., 2008).

Significant departures from null models of CSR, HPP, random labelling and independence were evaluated by means of the 5thlowest and the 5th-highest values of 999 Monte Carlo simulations in order to generate $99 \%$ simulation envelopes, up to $r=5 \mathrm{~m}$ (i.e. the maximum scale at which plant-plant interactions occur). We examined the significance levels of the simulation envelopes employing the Goodness-of-fit test proposed by Diggle (2003), which gives a summary statistic $u_{i}$ representing the total square deviation between the observed and expected patterns across the distance interval of interest $(r=5 \mathrm{~m}$ in this case; Loosmore and Ford, 2006). All analyses were performed with the grid-based software Programita for point pattern analysis (Wiegand and Moloney, 2004).

\section{Results}

Subzones T2, E1 and D2 showed (in this order) the largest number of individuals. Subzone D2 also presented the highest rates of survivorship. Rates of mortality and recruitment were very high in all subzones, with the exception of T2 and E2. Subzones D1 and E2 exhibited the highest rates of mortality, whereas the highest rates of recruitment appeared in T2 and E3 (Table 1).

Analyses in 2001 of changes in spatial point patterns at community level in the different subzones of the landslide (Fig. 2) revealed significant regularity at small spatial scales in subzones E2 and D2, and significant aggregation in E1. The other subzones showed random patterns. In 2002, these random patterns became significantly aggregated in E3, T1 and T2. Significant regularity persisted in E2 and D2 and significant aggregation in neighbourhoods of up to $r<1.3 \mathrm{~m}$ persisted in E1. In subzone E1 we also detected significant regularity at intermediate scales.

As for mortality analyses, the spatial pattern of both dead and surviving individuals was completely random in all subzones except in E1 (Fig. 3). Herein, both dead and surviving individuals showed significant aggregation up to $r<0.5$ and $1 \mathrm{~m}$, respectively (Fig. 3A). Dead and surviving individuals, however, were significantly segregated within neighbourhoods of $r<2 \mathrm{~m}$ (Fig. 3B). Summary statistics $g_{12}(r)-g_{11}(r)$ and $g_{21}(r)-g_{22}(r)$ were both below the simulation envelopes (Fig. $3 \mathrm{C}$ ), a fact that indicates that dead and surviving individuals are surrounded by individuals of the same type in greater abundance than by individuals of the other type. This indicates that there was no additional pattern affecting mortality of individuals. More importantly, values of the summary statistic $g_{1,1+2}(r)-g_{2,1+2}(r)$ were also below the simulation envelopes, which indicates density-dependent survival (Fig. 3D).

Recruitment analyses performed in erosional zones showed segregation between recruited and surviving individuals in E1 and E3, but not in E2 (Fig. 4A). Analyses of species interactions in the transitional subzones showed independence between spatial patterns of $D$. incanum and $D$. nicaraguense in T1c, and segregation between individuals of $D$. nicaraguense and $I$. guatimalensis up to $0.5 \mathrm{~m}$ in $\mathrm{T} 2 \mathrm{~d}$ (Fig. 4B).

\section{Discussion}

\subsection{Erosional subzones}

Some of the results obtained in erosional subzones clearly point toward positive interactions as the pattern-creating process, as predicted in our first hypothesis. The aggregated patterns found in subzone E1 are similar to those observed in other stressful environments such as semi-arid shrublands (Rayburn et al., 2011) and savannas (Schleicher et al., 2011), and high-mountain communities (Fajardo et al., 2008). We also detected an increase in aggregation over the study period, as found by Malkison and Kadmon (2007), and Felinks and Wiegand (2008) in early successional communities. On the contrary, we found that the pattern of new recruited individuals was independent of (subzone E1), or showed repulsion to (subzones E1 and E3), surviving individuals (Fig. 4 and S4). López et al. (2010) found similar patterns of repulsion between juvenile cacti and adult shrubs in the Bolivian Prepuna and explained these results by the high predictability of rain in this ecosystem. In arid 


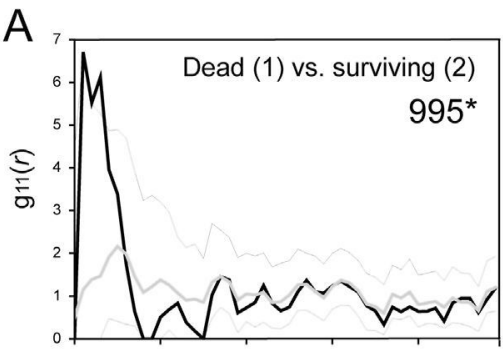

C

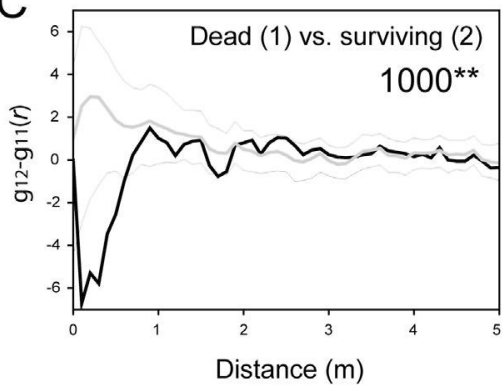

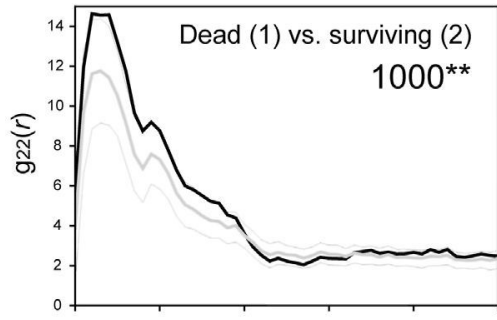

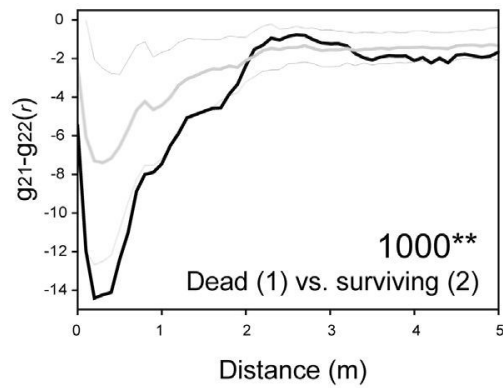

$\mathrm{B}$
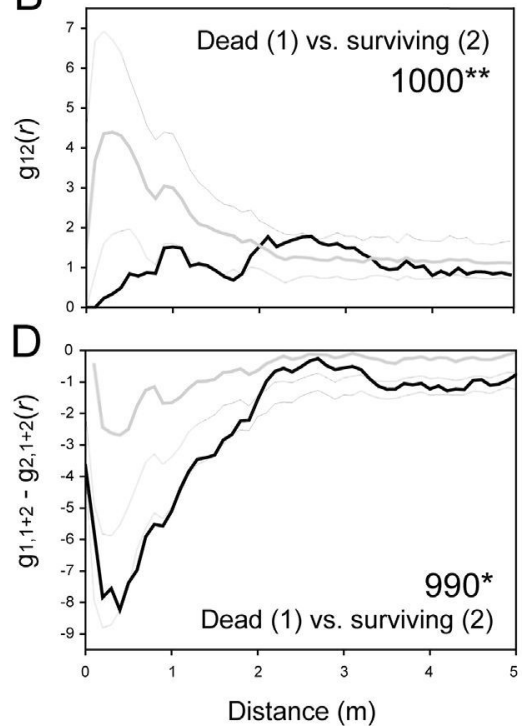

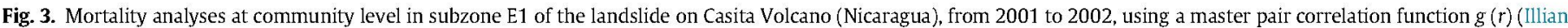

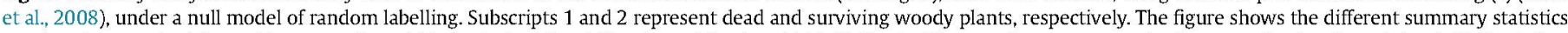

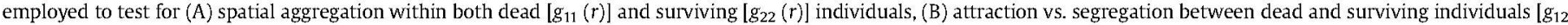

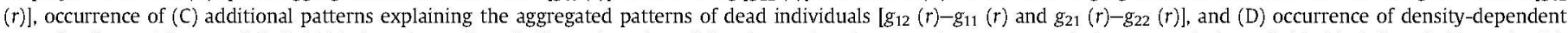

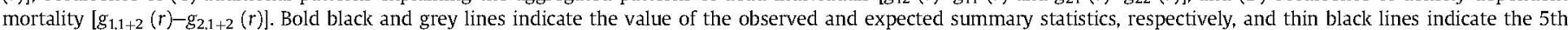

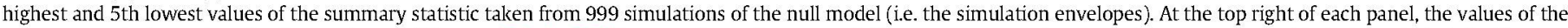

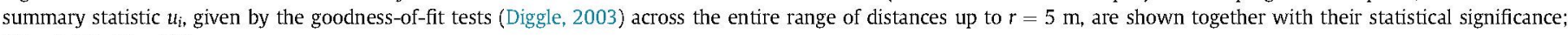
${ }^{* *} P<0.001,{ }^{*} P<0.05$.

and semi-arid areas precipitation is generally highly variable in time and space and regulates germination and establishment of seedlings, which require facilitation by adult plants (Schwinning et al., 2004). In the Bolivian Prepuna, however, annual rainfall is relatively predictable, which contributes to providing less stressful conditions and gives new seedlings the possibility of germinating in open spaces (López et al., 2010). The same explanation may apply for the repulsion patterns between surviving and recruited individuals found in the erosional zones of the Casita Volcano landslide. In these zones substrates are infertile and harsh, but the landslide is located in a region of dry tropical climate which receives $1250 \mathrm{~mm}$ of highly predictable, average rainfall from May to November (INETER, 2005). Our results therefore indicate that recruits of woody pioneer species within the erosional zones are capable of establishing in open spaces without requiring facilitation from plants already established.

Moreover, the results of mortality analyses in subzone E1 clearly showed that the likelihood of survival of an individual is significantly greater within high-density clumps (Fig. 3C). All these facts suggest that in subzone $\mathrm{E} 1$, positive interactions occur among surviving (i.e. already established) woody plants. In harsh sites, facilitative effects in the neighbourhood of established individuals could result from (i) a reduction of temperature and evapotranspiration extremes by shading (Haase, 2001), (ii) an improvement of soil nutrient status by accumulation of litter and the subsequent enrichment of soil organic matter (Walker and del Moral, 2003), (iv) a retention of woody seedlings (i.e. physical barriers sensu Francescato et al., 2001), and (v) a reduction of weed species cover, which can favour the establishment of late-successional species (i.e. indirect facilitation sensu Walker et al., 2010b). Facilitation by shading leads to a clear directionality in the spatial associations among woody plants (Haase, 2001), and these patterns were not observed in subzone E1 (E. Velázquez, pers. obs.). Additionally, patterns of density-dependent survival were detected up to $1-2 \mathrm{~m}$
(Fig. 3 and S2), that is, up to much larger spatial scales than those occupied by the crowns of the shrubs and tree saplings occurring in this subzone. The two dominant species in this subzone, $W$. urens and $T$. micrantha, which also comprised the highest proportion of established and dead individuals (Table 1), both present erect individuals and therefore do not possess the appropriate architectural characteristics to act as physical barriers (Felinks and Wiegand, 2008). These two species, however, have a high litterfall production and their leaves present high contents of nutrients such as $\mathrm{Mn}$ and $\mathrm{Cu}$, which are not very abundant in harsh sites (Valencia-Duarte, 2012; da Trindade and Coelho, 2012). All these facts suggest that in subzone E1, where nutrient concentrations were extremely low (Velázquez and Gómez-Sal, 2008), the observed patterns of density-dependent survival in E1 might result from the development of fertility islands (sensu Walker and del Moral, 2003) around established individuals of $W$. urens and T. micrantha, which facilitate the establishment of individuals of these and other species through soil nutrient improvement. This hypothesis is supported by the spatial patterns of significant aggregation at small scales and regularity at intermediate scales observed in E1 in 2002 (Fig. 2), which indicates the existence of clearly differentiated clusters (T. Wiegand, pers. comm.), which is also supported by the fact that, at small spatial scales dead individuals were aggregated, as were survivors (Fig. $3 \mathrm{~A}$ ), but both groups were segregated from each other (Fig. 3B).

The spatial patterns in subzones E2 and E3 do not indicate facilitative effects among established woody individuals. In subzone E2, regular patterns persisted over the 2001-2002 period. This subzone presented a steep slope (Velázquez and Gómez-Sal, 2008), which has a highly negative influence on colonization of woody plants on landslides (Walker et al., 2013) by its association with post-landslide erosion (Walker and Shiels, 2008). Therefore, the continuation of regular spatial patterns in this subzone over the study period might be due to removal of early colonizing 
A
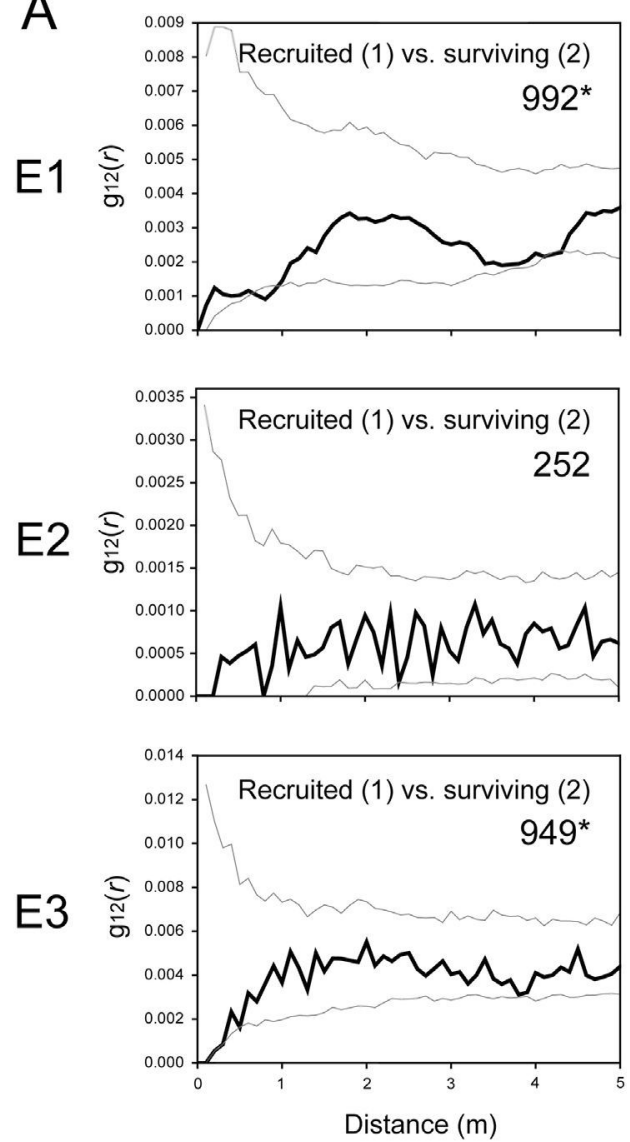
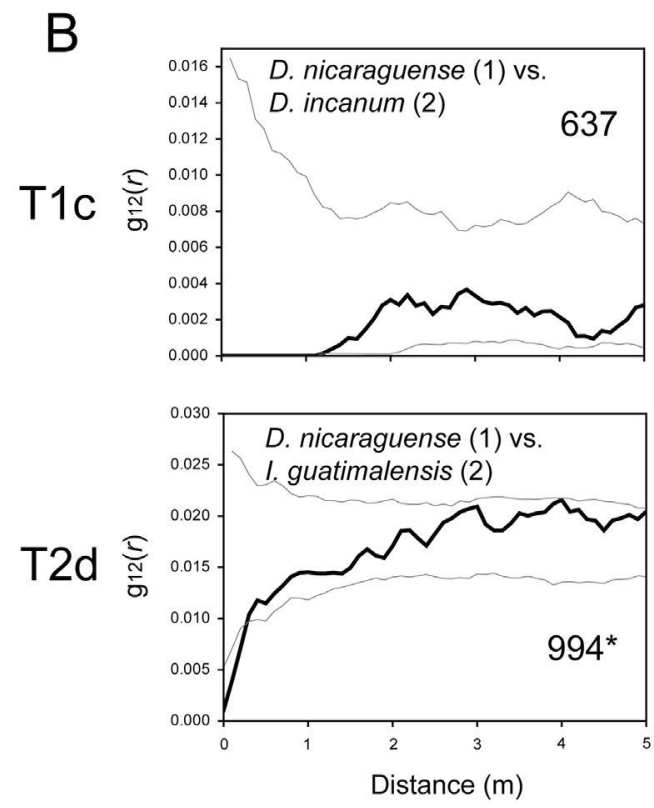

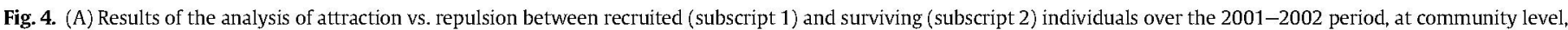

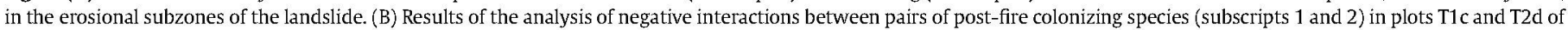

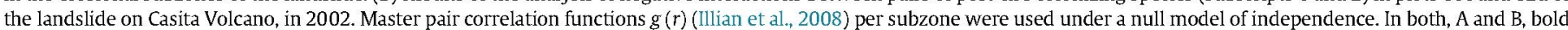

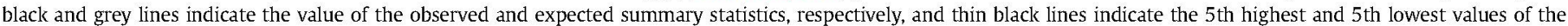

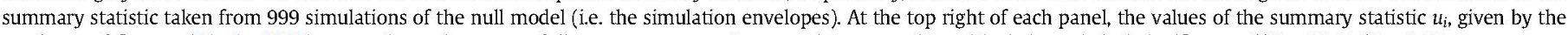
goodness-of-fit tests (Diggle, 2003) across the entire range of distances up to $r=5 \mathrm{~m}$, are shown together with their statistical significance; ${ }^{* *} P<0.001$, ${ }^{*} P<0.05$.

propagules through erosion, which was also likely to cause sudden and unexpected changes in species composition and diversity of woody plant communities between 1999 and 2001 (Velázquez and Gómez-Sal, 2008). Moreover, according to our results, patchy distributions of soil resources might have affected spatial patterns of mortality of $W$. urens individuals in this subzone (Fig. S3C). The high mortality rate in E2 (Table 1) and the strong variations in soil nutrient contents among plots of this subzone (Velázquez and Gómez-Sal, 2008, 2009a) provide support for this hypothesis. Conversely, in E3 recruitment was much more marked than mortality over the 2001-2002 period (Table 1). This subzone was colonized later than E1 and E2 (Velázquez and Gómez-Sal, 2007, 2008) and the increase in aggregation detected over the study period was strongly determined by the aggregated patterns of $W$. urens, which comprised the largest proportion of recruited individuals (Table 1, Fig. S1).

\subsection{Depositional subzones}

With regard to depositional subzones, prevalence of regular patterns (Fig. 2) point toward negative interactions among woody plants in D2, as we predicted in our fourth hypothesis. However, in this zone mortality was a random event (Goreaud and Pélissier, 2003). Moreover, the similarity between results at community and population level in subzone D2 (Fig. 2 and S1) suggests that mortality patterns are strongly driven by intra-specific competitive effects among individuals of the dominant species $T$. micrantha (Velázquez and Gómez-Sal, 2009b). Conversely, in subzone D1 the change from random to (non-significantly) aggregated spatial patterns is largely determined by the clearcutting of juvenile individuals of $T$. micrantha and $M$. calabura, and the subsequent germination of seedlings of Guazuma ulmifolia over the 2001-2002 period (Velázquez and Gómez-Sal, 2008). Recruits of this light demanding species formed variable-sized clumps in canopy openings and left a clear imprint on the spatial patterns of 2002 (Fig. S1).

\subsection{Transitional subzones}

In the transitional subzones, as we hypothesised, burning of the existing vegetation and the subsequent spread of several opportunistic species caused a clear shift from random to significantly aggregated patterns over the 2001-2002 period (Rebertus et al., 1989). In both $T 1$ and $T 2$, patterns of $D$. nicaraguense were largely responsible for the significant aggregation observed at community level (Fig. 2 and S1). Aggregation was particularly marked in T2 because in this subzone the rate of recruitment was particularly high (Table 1) due to post-fire colonization of a large number of individuals of $D$. nicaraguense and $I$. guatimalensis. The significant repulsion observed between point patterns of $D$. nicaraguense and 
I. guatimalensis might be due to the existence of negative in teractions between these two opportunistic species. These results are similar to those of De Luis et al. (2008) for Mediterranean shrublands over the first few years after fire occurrence.

\subsection{Limitations}

In addition to the aforementioned processes, other mechanisms could have been also involved in the creation of spatial patterns of woody pioneer plants. For instance, shading in the understory of pioneer forests of the subzone D2 might have promoted germination of small seedlings of late-successional species (Velázquez and Gómez-Sal, 2008). However, the number of these seedlings was too low to produce spatial patterns of association between surviving individuals of $T$. micrantha and recruited individuals of other species.

Moreover, we were able to detect the spatial signature of the main drivers of early succession considering just a short time frame of two years. This has been possible because over the first few years of succession spatial point patterns of pioneer species markedly change (Malkison and Kadmon, 2007; Felinks and Wiegand, 2008), particularly in regions of tropical climate, where this process is rapid (Walker et al., 1996). However, the examination of other processes, such as facilitation of juvenile pioneer trees by mature ones (Nishimura and Kohyama, 2002), may require longer time frames or a space-for-time substitution approach (Walker et al., 2010a). It is also important to point out that, although we have defined ecologically informed, a-priori hypotheses in order to avoid problems associated with pattern-process inference (McIntyre and Fajardo, 2009), our results are still purely descriptive. To elucidate the underlying processes that we hypothesise, further experimentation is required.

\subsection{Conclusions}

To summarise, our research demonstrates that the spatial patterns indicative of positive and negative interactions among woody plants between 2001 and 2002 were more prevalent in the most and least stressful areas of the landslide on Casita Volcano. These results are in agreement with the stress-gradient hypothesis, which states that the relative importance of facilitation and competition varies inversely across gradients of abiotic stress (Bertness and Callaway, 1994). The spatial signatures of these processes, however, have been distorted by the effects of natural and human-induced disturbances. All these processes have given rise to much higher rates of mortality and recruitment than those recorded over the first few years of succession in abandoned fields located in areas of dry (Maza-Villalobos et al., 2013) and wet (van Breugel et al., 2007) tropical climate.

Our results therefore indicate that large landslides comprising zones largely differing in substrate stability and fertility form a template in which the assembly of early successional plant communities might be driven by a much larger array of plant-plant interactions than previously thought. These interactions can be approached by mapping the spatial locations of woody individuals and performing non-destructive spatial point pattern analyses on the resulting point maps. Projections for increased hurricane intensity and frequency in the Atlantic over the next few decades may imply a higher landslide occurrence in the Central American isthmus (Bender et al., 2010). Thereby, there is critical need to improve our understanding of the major biotic processes driving landslide succession in this region.

\section{Acknowledgements}

This research is part of the collaborative programme between the "Universidad de Alcalá" (Madrid, Spain) and the "Universidad Nacional Autónoma de Nicaragua-León", and was supported by a grant from the "3rd Scientific Research and Technological Innovation Program" of the Madrid Regional Govt. Pedrarias Dávila and Aníbal Rodríguez were of great help in planning and conducting the fieldwork, respectively. Ricardo Rueda and Dania Paguaga helped us to identify the plant species. We are very grateful to the Sevilla family in the community of "Pikin Guerrero", who provided accommodation and supported our fieldwork. Eduardo Velázquez is currently supported by the SpatioDiversity project (Grant number 233066) of the European Research Council. Marcelino de la Cruz is supported by the REMEDINAL2 project (P2009/AMB-1783) of the Madrid Regional Govt. and by the ISLAS project (CGL2009-13190C03-02) of the Spanish Ministry of Economy and Competitiveness. Earlier versions of the manuscript benefited from comments by P.M. Dixon, L. R. Walker, A. Shiels, J. Rodrîguez-Pérez and S. Getzin. We wish also to acknowledge the advice provided by $\mathrm{T}$. Wiegand with spatial point pattern analyses and the help of Lucía Gálvez, Fabio Bartolomei and Cormac de Brun for improving the English.

\section{Appendix A. Supplementary data}

Supplementary data related to this article can be found at http:// dx.doi.org/10.1016/j.actao.2014,09.001.

\section{References}

Bailey, T.C., Gatrell, A.C., 1995. Interactive Spatial Data Analysis. Longman Scientific and Technical, Prentice Hall, Harlow, United Kingdom.

Barot, S., Gignoux, J., 2003. Neighbourhood analysis in the savanna palm Borassus aethiopum: interplay of intraspecific competition and soil patchiness. J. Veg. Sci. 14, 79-88.

Bender, M.A., Knutson, T.R., Tuleya, R.E., Sirutis, J.J., Vecchi, G.A., Garner, S.T., Held, I.M., 2010. Modeled impact of anthropogenic warming on the frequency of intense Atlantic hurricanes. Science 327, 454-458.

Bertness, M.D., Callaway, R., 1994. Positive interactions in communities. Trends Ecol Evol. 9, 191-193.

Callaway, R.M., Brooker, R.W., Choler, P., Kikvidze, Z, Lortie, C., Michalet, R, Paolini, L., Pugnaire, F.I., Newingham, B., Ascheloug, E.T., Armas, C., Kikodze, D., Cook, B.J., 2002. Positive interactions among alpine plants increase with stress. Nature 417, 844-848.

Callaway, R.M., Pugnaire, F.I., 2008. Facilitation in plant communities. In: Pugnaire, F.I., Valladares, F. (Eds.), Handbook of Functional Plant Ecology. Marcel Dekker, New York, pp. 623-648.

Casper, B.B., Schenk, H.J. Jackson, R.B., 2003. Defining a plant's belowground zone of influence. Ecology 84, 2312-2313.

Colasanti, R.L., Hunt, R., 1997. Resource dynamics and plant growth: a selfassembling model for individuals, populations and communities. Funct. Ecol. $11,133-145$.

da Trindade, D.F., Coelho, G.C., 2012. Woody species recruitment under monospecific plantations of Pioneer trees - facilitation or inhibition? iForest 5, 1-5.

De Luis, M., Raventós, J., Wiegand, T., González-Hidalgo, J.C., 2008. Temporal and spatial differentiation in seedling emergence may promote species coexistence in Mediterranean fire-prone ecosystems. Ecography 31, 620-629.

Diggle, P.J., 2003. Statistical Analysis of Spatial Point Patterns, second ed. Arnold, London.

Dixon, P.M., 2002. Ripley's K function. In: El-Shaarawi, A.H., Piergorsch, W.W. (Eds.), Ripley's K Function. John Wiley \& Sons Ltd., New York, pp. 1796-1803.

Fajardo, A., Alaback, P., 2005. Effects of natural and human disturbances on the dynamics and spatial structure of Nothofagus glauca in south-central Chile. J. Biog. 32, 1811-1825.

Fajardo, A., Ouiroz, C.L., Cavieres, L.A., 2008. Spatial patterns in cushion-dominated plant communities of the high Andes of Central Chile: how frequent are positive associations? J. Veg. Sci. 19, 87-96.

Felinks, B., Wiegand, T., 2008. Exploring spatiotemporal patterns in early stages of primary succession on former lignite mining sites. J. Veg. Sci. 19, 267-276.

Fetcher, N., Haines, B.L., Cordero, R.A., Lodge, D.J., Walker, L.R., Fernández, D.S., Lawrence, W.T., 1996. Responses of tropical plants to nutrients and light on a landslide in Puerto Rico. J. Ecol. 84, 331-341. 
Francescato, V., Scotton, M., Zarin, D.J., Innes, J.C., Bryant, D.M., 2001. Fifty years of natural revegetation on a landslide in Franconia Notch, New Hampshire, U.S.A. Can. J. Bot. 79, 1477-1485.

Getzin, S., Dean, C., He, F., Trofymow, J.A., Wiegand, K., Wiegand, T., 2006. Spatial patterns and competition of tree species in a Douglas-fir chronosequence on Vancouver Island. Ecography 29, 671-682.

Goreaud, F., Pélissier, R., 2003. Avoiding misinterpretation of biotic interactions with the intertype $\mathrm{K}_{12}$ function: population independence vs. random labelling hypotheses. J. Veg. Sci. 14, 681-692.

Haase, P., 2001. Can isotropy vs. anisotropy in the spatial association of plant species reveal physical vs. biotic facilitation? J. Veg. Sci. 12, 127-136.

Hartle, R.T., Fernández, G.C.I., Nowak, R.S., 2006. Horizontal and vertical zones of influence for root systems of four Mojave Desert shrubs. J. Arid. Env. 64, 586-603.

He, F., Duncan, R.P., 2000. Density-dependent effects on tree survival in an oldgrowth Douglas fir forest. J. Ecol. 88, 676-688.

Illian, J., Penttinen, A., Stoyan, H., Stoyan, D., 2008. Statistical Analysis and Modelling of Spatial Point Pattems. John Wiley \& Sons, Ltd, Chichester, United Kingdom.

INETER, 2005. Resumen Meteorológico 1966-2004. Instituto Nicaragüense de Estudios Territoriales, Managua.

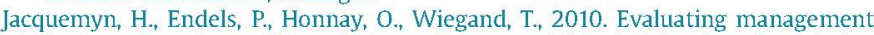
interventions in small populations of a perennial herb Primula vulgaris using spatio-temporal analyses of point patterns. J. App. Ecol. 47, 413-440.

Kerle, N., de Vries, B.V., Oppenheimer, C., 2003. New insight into the factors leading to the 1998 flank collapse and lahar disaster at Casita volcano, Nicaragua. B. Volcanol. $65,331-345$.

Law, R. Illian, J., Burslem, D.F.R.P., Gratzer, G., Gunatilleke, C.V.S Gunatilleke, I.A.U.N., 2009. Ecological information form spatial patterns of plants: insights from point process theory. J. Ecol. 97, 616-628.

Loosmore, N.B., Ford, E.,D., 2006. Statistical inference using the G or K point pattern spatial statistics. Ecology 87, 1925-1931.

López, R.P., Larrea-Alcázar, D., Zenteno-Ruiz, F., 2010. Spatial pattern analysis of dominant species in the Prepuna: gaining insight into community dynamics in the semi-arid, subtropical Andes. J. Arid. Env. 74, 1534-1539.

Malkison, D., Kadmon, R., 2007. Vegetation dynamics along a disturbance gradient: spatial and temporal perspectives. J. Arid. Env. 69, 127-143.

Maza-Villalobos, S., Poorter, L., Martínez-Ramos, M., 2013. Effects of ENSO and temporal rainfall variation on the dynamics of successional communities in oldfield succession of a tropical dry forest. PLoS One 8, e82040.

Martin, Y., Rood, K., Schwab, J.W., Church, M., 2002. Sediment transfer by shallow landsliding in the Queen Charlotte Islands, British Columbia. Can. J. Earth Sci. 39, 189-205.

McIntyre, E.J.B., Fajardo, A., 2009. Beyond description: the active and effective way to infer processes from spatial patterns. Ecology 90, 45-56.

Moustakas, A., Wiegand, K., Getzin, S., Ward, D., Meyer, K.M., Guenther, M. Mueller, K.-H., 2008. Spacing patterns of an Acacia tree in the Kalahari over a 61-year period: how clumped becomes regular and vice-versa, 33, 355-364.

Nishimura, T.B., Kohyama, T., 2002. Formation and maintenance of community boundaries in a sub-alpine forest landscape in northern Japan. J. Veg. Sci. 13, $555-564$.

Raventós, J., Wiegand, T., De Luis, M., 2010. Evidence for the spatial segregation hypothesis: a test with nine year survivorship data in Mediterranean shrubland. Ecology $91,2110-2120$.

Raventós, J., Wiegand, T., Maestre, F.T., de Luís, M., 2012. A resprouter herb reduces negative density-dependent effects among neighboring seeders after fire. Acta Oecol. $38,17-23$.

Rayburn, A.P., Schiffers, K., Schupp, E.W., 2011. Use of precise spatial data for describing spatial patterns and plant interactions in a diverse Great Basin shrub community. Plant Ecol. 212, 585-594.

Rebertus, A.J., Williamson, B.G., Moser, E.B., 1989. Fire-induced changes in Quercus laevis spatial pattern in Florida sandhills. J. Ecol. 77, 638-650.

Restrepo, C., Walker, L.R., Shiels, A.B., Bussman, R. Claessens, L., Fisch, S., Lozano, P. Negi, G., Paolini, L., Poveda, G., Ramos-Scharrón, C., Richter, M., Velázquez, E.,
2009. Landsliding and its multiscale influence on mountainscapes. Bioscience $59,685-698$.

Rice, J.M., Halpern, C.B., Antos, J.A., Jones, J.A., 2012. Spatio-temporal patterns of tree establishment are indicative of biotic interactions during early invasion of a montane meadow. Plant Ecol. 213, 555-568.

Schenk, H.J., Holzapfel, C., Hamilton, I.G., Mahall, B.E., 2003. Spatial ecology of a small desert shrub on adjacent geological substrates. J. Ecol. 91, 383-395.

Schleicher, J., Meyer, K.M., Wiegand, K., Schurr, F.M., Ward, D., 2011. Disentangling facilitation and seed dispersal from environmental heterogeneity as mechanisms generating associations between savanna plants. J. Veg. Sci. 22 $1038-1048$.

Schwinning, S., Sala, O.E., Loik, M.E., Ehleringer, J.R., 2004. Thresholds, memory, and seasonality: understanding pulse dynamics in arid/semi-arid ecosystems. Oecologia 141, 191-193.

Shiels, A.B., Walker, L.R., Thompson, D.B., 2006. Organic matter inputs create variable resource patches on Puerto Rican landslides. Plant Ecol. 184, 223-236.

Stevens, W.D., Ulloa-Ulloa, C., Pool, A., Montiel, O.M., 2001. Flora de Nicaragua. Missouri Botanical Garden Press, St. Louis.

Stoll, P., Bergius, E., 2005. Pattem and process: competition causes regular spacing of individuals within plant populations. J. Ecol. 93, 395-403.

Stoyan, D., Stoyan, H., 1994. Fractals, Random Shapes and Point Fields: Methods of Geometrical Statistics. Wiley, Chichester.

van Breugel, M., Bongers, F., Martínez-Ramos, M., 2007. Species dynamics during early secondary forest succession: recruitment, mortality and species turnover. Biotropica 35, 610-619.

Valencia-Duarte, J., Trujilllo-Ortiz, L.N., Vargas-Ríos, O., 2012. Dinámica de la vegetación en un enclave semiárido del río Chicamocha Colombia. Biota Colomb $13,40-59$.

Velázquez, E., 2007. Sucesión ecológica temprana en un deslizamiento de ladera de grandes dimensiones en ambiente tropical seco (Volcán Casita, Nicaragua) (Ph.D. Thesis Dissertation).

Velázquez, E., Gómez-Sal, A., 2007. Environmental control of early succession on a large landslide in a tropical dry ecosystem. Biotropica 39, 601-609.

Velázquez, E., Gómez-Sal, A., 2008. Landslide early succession in a neotropical dry forest. Plant Ecol. 199, 295-308.

Velázquez, E., Gómez-Sal, A., 2009a. Different growth strategies in the tropical pioneer tree Trema micrantha during succession on a large landslide on Casita Volcano, Nicaragua. J. Trop. Ecol. 25, 1-12.

Velázquez, E., Gómez-Sal, A., 2009b. Changes in the herbaceous communities on the landslide of the Casita Volcano, Nicaragua, during early succession. Folia Geobot. $44,1-18$.

Walker, L.R., del Moral, R., 2003. Primary Succession and Ecosystem Rehabilitation. Cambridge University Press, Cambridge.

Walker, L.R., Landau, F.H., Velázquez, E., Shiels, A.B., Sparrow, A.D., 2010a. Early successional woody plants facilitate and ferns inhibit forest development on Puerto Rican landslides. J. Ecol. 98, 625-635.

Walker, L.R., Shiels, A.B., 2008. Post-disturbance erosion impacts carbon fluxes and plant succession on recent tropical landslides. Plant Soil 313, 205-216.

Walker, L.R., Shiels, A.B., Bellingham, P.J., Sparrow, A.D., Fetcher, N., Landau, F.H., Lodge, D.J., 2013. Changes in abiotic influences on seed plants and ferns during 18 years of primary succession on Puerto Rican landslides. J. Ecol. 101, 650-661.

Walker, L.R., Zarin, D.J., Fetcher, N., Myster, R.W., Johnson, A.H., 1996. Ecosystem development and plant succession on landslides in the Caribbean. Biotropica $28,566-576$

Walker, L.R., Wardle, D.A., Bardgett, R.D., Clarkson, B.D., 2010b. The use of chronosequences in studies of ecological succession and soil development. J. Ecol. $98,725-736$

Wiegand, T., Gunatilleke, S., Gunatilleke, N., 2007. Species associations in a heterogeneous Sri-Lankan dipterocarp forest. Amer. Nat. 170, E77-E95.

Wiegand, T., Moloney, A., 2004. Rings, circles and null-models for point pattern analysis in ecology. Oikos 104, 209-229.

Yu, H., Wiegand, T., Yang, X., Ci, L., 2009. The impact of fire and density-dependent mortality on the spatial patterns of a pine forest in the Hulun Buir sandland, Inner Mongolia, China. For. Ecol. Manag. 257, 2098-2107. 